\title{
AN ANALYSIS OF COST EFFICIENCY IN SWISS MULTI-UTILITIES *
}

\author{
Mehdi Farsi Massimo Filippini \\ mfarsi@ethz.ch mfilippini@ethz.ch \\ Department of Management, Technology and Economics, ETH Zurich \\ Zurichbergstr. 18, CH-8032 Zurich, Switzerland \\ Tel. +41-44-63206 50, Fax. +41-44-632 1050 \\ and \\ Department of Economics, University of Lugano
}

\begin{abstract}
This study presents an empirical analysis of the cost efficiency of a sample of Swiss multi-utilities operating in the distribution of electricity, natural gas and water. The multi-utilities that operate in different sectors are characterized by a strong unobserved heterogeneity. Therefore the measurement of their performance poses an important challenge for the regulators. The purpose of this paper is to study the potential advantages of recently developed panel data stochastic frontier models in the measurement of the level of efficiency for multi-utility companies. These models are estimated for a sample of 34 multi-output utilities operating from 1997 to 2005. The alternative models are compared regarding the cost function slopes and inefficiency estimates. For the inefficiency estimates, the correlation between different models and the effect of econometric specification have been analyzed. The results suggest that the inefficiency estimates are substantially lower when the unobserved firm-specific effects are taken into account.
\end{abstract}

JEL Classification: C33, D24, L11, L25, L94, L95

Keywords: cost function; efficiency; panel data; multi-output utilities

\footnotetext{
* This paper is based upon the results of a research project (Farsi and Filippini, 2007) sponsored by Switzerland's State Secretariat for Economic Affairs (SECO). We gratefully acknowledge their financial support but also the extraordinary cooperation of their staff especially Peter Balastèr, throughout the project. We also wish to thank Aurelio Fetz for his excellent assistance in compiling the data used in this study. In revising the paper, we benefited from the insightful comments from Richard Tol, Guido Pepermans and two anonymous referees, which are greatly appreciated. All remaining errors and omissions are ours. The views expressed in this paper do not necessarily reflect the position of any sponsoring agency.
} 


\section{Introduction}

Along with the recent waves of liberalization and deregulation in network industries throughout Europe, the authorities are increasingly concerned about the cost efficiency $^{1}$ of the utilities that, due to their natural monopoly characteristics, are not fully liberalized. Because of their considerable economies of scale, a direct introduction of competition is not optimal in sectors such as power, gas and water distribution. Instead, incentive regulation can be used to ensure (or maximize) the productive efficiency of the locally monopolistic companies. Unlike the traditional contracting systems based on a reasonable Rate of Return, the incentive contracts are designed to induce incentives for reducing costs and increasing efficiency. Most incentive regulation schemes use benchmarking to evaluate the productive performance of the regulated companies in order to reward/punish them accordingly. Based on their efficiency performance, companies are allowed to keep some of their profits/savings through either differentiated price caps or adjustments in budget or network access fees.

Several European countries have introduced incentive regulation schemes only in the electricity sector (Farsi, Fetz and Filippini, 2007a; Crouch, 2007), some others also in the water and gas sectors (Saal et al., 2007; Antonioli and Filippini, 2001, Casarin, 2007). Although Switzerland has not yet implemented any incentive regula-

\footnotetext{
${ }^{1}$ Consistent with the economics literature on production theory (e.g. Farrel, 1957; Chambers, 1988) here, the term efficiency is referred to the efficiency in production or productive efficiency. In this context, the definition of efficiency is not based on optimality in an economic system in the Pareto sense (as in Debreu, 1951), but as noted by Fried et al. (2008), is the relative difference between the firm's observed inputs/outputs and the optimal production plan from the firm's standpoint. This relative efficiency in terms of costs is generally defined as cost efficiency (Kumbhakar and Lovell, 2000). While it is important to distinguish this concept from Pareto efficiency, the alternative term cost effectiveness (e.g. Kopsakangas-Savolainen and Svento, 2008) might lead to certain confusion, because of the common usage of that term in other strands of economics literature, as a comparative measure of cost-benefit or input-output ratios among several technologies (or policies). In general, cost effectiveness aims at finding the best technology, whereas cost efficiency or in general, productive efficiency is used to assess various possible plans of production using similar technologies that can ideally be characterized as a single technology.
} 
tion system, the actual debates suggest that the regulators will probably follow similar reforms in the near future. ${ }^{2}$

In spite of a relatively common usage in each one of the distribution sectors, the direct application of benchmarking analysis in the regulation of multi-utilities has hardly been explored. This is especially interesting in Switzerland and some other European countries, where multi-utilities dominate the distribution sectors in electricity, natural gas and water. In general, given the differentiated pace of regulatory reforms in electricity, gas and water sectors, the multi distribution utilities are regulated with instruments that vary across the three sectors of activity. ${ }^{3}$

To our knowledge there is no reported empirical application of efficiency measurement in the multi-utility sector. This may perhaps be considered in line with arguments in favor of unbundling the multiple-utilities into separate legal entities. In fact, horizontal unbundling is a recurring subject of the public policy debates both in the EU and Switzerland. However, the dominance of multi-utilities in Switzerland is not expected to be affected by the ongoing reforms. According to the observed tendencies in the EU regulatory reforms, the multi-utilities especially those with moderate and small networks (less than 100,000 customers), will remain exempt from unbundling requirements.

Noting the dominance of multi-utilities operating in electricity, gas and water distribution in Switzerland and in some other European countries, an important question is whether the benchmarking methods can be applied to multi-utilities as well as single-output distribution utilities. From a technical point of view it is possible to perform an analysis of cost efficiency for a sample of multi-utilities. Provided that there

\footnotetext{
${ }^{2}$ For instance, from the beginning of 2009 several changes will be implemented in the electricity sector. These reforms allow the regulation authority at the federal level to use benchmarking analysis for the acceptance of the tariffs.

${ }^{3}$ In particular, the Swiss government has not yet undertaken any reform initiative for the gas and water sectors. This implies that the distribution tariffs in these two sectors will continue to be regulated directly by the local municipality with a rate-of-return approach. See Farsi and Filippini (2007) for more details.
} 
are a sufficient number of multi-utilities for a sensible global benchmarking analysis, one could argue that at least theoretically a "global” benchmarking provides more reliable results compared to a "sectorial" approach, to the extent that the integrated multi-utilities are more comparable to each other than to specialized companies that do not use the potential synergies across the sectors. However, as we will discuss later, the strong heterogeneity of the production process of this type of utilities can create some difficulties.

Moreover, in practice, if the historical development of regulation systems can be a guide, the sectorial approach has clear advantages regarding implementation and political acceptance. In fact, in several European countries, including Switzerland, separate regulation authorities for gas, electricity and water have been created. Some of these authorities use incentive regulation schemes that make use of inefficiency estimates while some others adopt traditional regulation systems such as rate of return regulation. In order to provide clear information to the individual regulation authority, the governments have generally required the multi-utilities to introduce an accounting unbundling of their activities. This implies that each individual regulator can perform a benchmarking analysis of the cost only for the sector of a multi-utility for which it is responsible. For instance, the Swiss regulation authority for the electricity sector (ELCOM) could perform a benchmarking analysis only for the electricity sector of the multi-utility.

However, the main problem of this sectorial approach results from the fact that in most cases only the electricity sector is regulated with incentive regulation schemes, in which case the multi-output companies could artificially shift part of the costs to the water and gas sectors for which the regulation does not foresee a benchmarking analysis. In these cases there is a clear risk that the incentive regulation instrument loses its effectiveness. To overcome this problem the regulators could consider combining the efficiency analysis of individual sectors with a global benchmarking for the whole company. Such combined analyses can throw some light on the patterns of inefficiency as well as cost shifting behavior. For instance, a large discrepancy between the inefficiency estimates of a given company (at the global and sectoral levels) could be interpreted as an indication of cost shifting behavior. 
The effectiveness of such regulation systems relies upon the accuracy of estimated efficiency levels of individual companies. However, due to a great variety of available methods of efficiency measurement and the observed discrepancy of results across different methods, benchmarking practice requires a methodology to adopt a single model among several legitimate approaches and specifications. This task is particularly complicated in network utilities in which unobserved firm-specific factors might be confounded with inefficiency. Obviously the problem of unobserved heterogeneity is more important in multi-output distributors that operate in several networks, each of which could have different types of cost drivers with specific characteristics.

Unobserved firm-specific heterogeneity can be taken into account with conventional fixed or random effects in a panel data model. In order to distinguish external heterogeneities from cost efficiency, Greene (2005a) proposed a model that integrates an additional stochastic term representing inefficiency in both fixed and random effects models. ${ }^{4}$ These models assume that the firm-specific heterogeneity does not change over time but sources of inefficiency vary both across firms and over time. In this paper we use a 'true random-effects' model (TRE), which is a random-constant frontier model, obtained by combining a conventional random-effects model with a skewed stochastic term representing inefficiency. The extended model includes separate stochastic terms for latent heterogeneity and inefficiency.

The empirical results reported in the literature obtained from TRE models suggest that modeling unobserved heterogeneity could significantly decrease the inefficiency estimates. ${ }^{5}$ This could lend certain support to the application of benchmarking methods in the regulation of strongly heterogeneous network industries, in which the conventional inefficiency estimates appear to be overstated. Provided that they can sufficiently control for the unobserved heterogeneity across firms, these methods can

\footnotetext{
${ }^{4}$ Kumbhakar (1991) proposed a similar approach using a three-stage estimation procedure. See also Heshmati and Kumbhakar (1994) and Kumbhakar and Hjalmarsson (1995) for two applications

${ }^{5}$ See for instance Greene (2004), Farsi, Filippini and Kuenzle (2005) and Alvarez, Arias and Greene (2004).
} 
be used to have a better estimate of inefficiency. However, the assumption that the time invariant part is heterogeneity rather than inefficiency could be unrealistic in cases where the persistent inefficiency is considerable. Therefore, it is crucial to compare the results with those obtained from other models that consider the time-invariant unexplained excess costs as inefficiency. In this paper we use random effects models proposed by Schmidt and Sickles (1984) and Pitt and Lee (1981), assuming timeinvariant inefficiencies and Battese and Coelli (1992) that allows for a uniform decline of inefficiency with time. Unlike TRE, these models do not allow for a separate time-invariant term, thus probably overstating the inefficiency. On the other hand, cost inefficiency is probably under-estimated in the TRE model. As we will discuss in Section 4, the results considered together could provide plausible lower and upper bounds for the inefficiency of single multi-utilities.

The purpose of this paper is to study the potential advantages of benchmarking models particularly the extended models such as Greene (2005) in an application to Switzerland's multi-output utilities. The models are estimated for a sample of 34 companies operating in Switzerland from 1997 to 2005. The alternative models are compared regarding the cost function slopes and inefficiency estimates. For the inefficiency estimates, the correlation between different models and the effect of econometric specification have been analyzed. The results suggest that the inefficiency estimates are substantially lower when the unobserved firm-specific effects are taken into account.

The rest of the paper is organized as follows: Section 2 presents the model specification and the methodology. The data are explained in section 3. Section 4 presents the estimation results and discusses their implications, and section 5 provides the conclusions.

\section{Stochastic frontier models for panel data}

The methods used for measuring technical, allocative and cost efficiency are commonly referred to as frontier approaches, classified into two main categories of 
linear programing methods and econometric approaches. ${ }^{6}$ The latter group, also known as Stochastic Frontier Analysis (SFA) is easily adaptable to panel data structure and therefore used in this study. In SFA models, first developed by Aigner, Lovell and Schmidt (1977) and Meeusen and van den Broeck (1977), the regression residuals are decomposed into a symmetric component representing statistical noise and a skewed term one representing inefficiency.

As opposed to cross-sections, in panel data the repeated observation of the same company over time allows an estimation of unobserved firm-specific factors, which might affect costs but are not under the firm's control. Individual companies operate in different regions with various environmental and network characteristics that are only partially observed. It is crucial for the regulator to disentangle such exogenous heterogeneities from inefficiency estimates. However the distinction between these two unobserved terms requires certain assumptions based on judgment. In early applications of SFA models to panel data (Pitt and Lee, 1981; Schmidt and Sickles, 1984; Battese and Coelli, 1988), the common assumption was that the productive efficiency is a time-invariant characteristic that can be captured by firm-specific effects in a random or fixed effects model.

A general form of a cost frontier based on these models can be written as:

$$
\ln C_{i t}=f\left(y_{i t}, w_{i t}\right)+u_{i}+v_{i t}
$$

where subscripts $i$ and $t$ denote the firm and the operation year, $C$ is the cost variable usually in logarithms and $\boldsymbol{y}$ and $\boldsymbol{w}$ are respectively vectors of outputs and input factor prices. The time-varying error component $v_{i t}$, typically a normal variable, represents the unobserved heterogeneity and random errors, whereas the time-invariant term $u_{i}$ is assumed to represent excess costs due to inefficiency. The latter term is considered with different distributions: While Pitt and Lee (1981) adopt a half-normal distribution that is, a normal distribution truncated at zero. Battese and Coelli (1988) extends the model to non-zero truncation points and Schmidt and Sickles (1984) propose two

\footnotetext{
${ }^{6}$ Murillo-Zamorano (2004) provides an account of advantages and shortcomings of each group. Other interseting surveys are Coelli et al. (2005), Simar (1992) and Kumbhakar and Lovell (2000).
} 
variations in which they relax the distribution assumptions respectively using Generalized Least Squares (GLS) and fixed-effect estimators. In particular, in the latter model, the individual effects $u_{i}$ can be correlated with the explanatory variables.

In more recent papers the random effects model has been extended to include time-variant inefficiency. Cornwell, Schmidt and Sickles (1990), Kumbhakar (1990), and Battese and Coelli (1992) are the important contributions that consider a time function to account for variation of efficiency. In particular the former paper proposes a flexible function of time with parameters varying among firms. In all these models, however, the unobserved external heterogeneity is suppressed in an iid error term across observations. This implies that the cost variations due to factors other than firm's efficiency are randomly assigned to each observation. This could be a restrictive assumption in network industries in which certain external cost drivers specific to environment and/or network complexity remain practically unchanged over fairly long periods of time.

To the extent that environmental factors and network characteristics do not change considerably over time, associating the time-invariant excess costs to external factors rather than inefficiency can be a sensible assumption. On the other hand, improvements in efficiency are usually linked to a dynamic learning process and adaptation to new technologies. While recognizing that these learning processes are relatively slow without adequate incentive regulation, we contend the managers' incentives for improvement are partly driven by the ubiquitous policy debates, expected regulatory reforms and criticisms by monitoring authorities. ${ }^{7}$ Therefore, it is assumed that inefficiencies are captured by the time-varying excess costs. These assumptions combined with the distribution assumption in line with the original frontier model al-

\footnotetext{
${ }^{7}$ In fact like many other European countries, in Switzerland, following the government's policy directives to introduce more competition in the electricity sector, since about the middle of the 1990's the public utilities have initiated internal re-organization mechanisms to improve competitiveness.
} 
low a disentanglement of inefficiencies from firm-specific heterogeneity captured by panel's individual effects. ${ }^{8}$

In fact, the SFA model in its original form (Aigner, Lovell and Schmidt, 1977) can be readily extended to panel data models, by adding a fixed or random effect in the model. Although similar extensions have been proposed by several previous authors, ${ }^{9}$ Greene (2005a,b) provides effective numerical solutions for both models with random and fixed effects, which he respectively refers to as "true" fixed and random effects models. Several recent studies such as Greene (2004), Farsi, Filippini and Kuenzle (2005), Alvarez, Arias and Greene (2004) and Tsionas (2002) have followed this line. Some of these models have proved a certain success in a broad range of applications in network industries in that they give more plausible efficiency estimates. ${ }^{10}$ These results raise an important question as to what extent the panel-data-adapted models can be used to have a better understanding of the inefficiencies and whether they can provide a reliable basis for benchmarking and incentive regulation systems in industries characterized by strong heterogeneity. This question is especially important in the multi-utility sector, in which the companies operate in multiple networks, entailing several network-specific heterogeneity dimensions.

Greene’s (2005a) 'true' cost frontier model can be written as:

$$
\ln C_{i t}=f\left(\boldsymbol{y}_{i t}, \boldsymbol{w}_{i t}\right)+\alpha_{i}+u_{i t}+v_{i t} .
$$

The term $\left(\alpha_{i}\right)$ is a normal i.i.d. in random-effects framework, or a constant parameter in fixed-effects approach. $u_{i t}$ and $v_{i t}$ are respectively a half-normal variable represent-

\footnotetext{
${ }^{8}$ There are evidently other feasible econometric specifications that can incorporate these assumptions. A remarkable example is the flexible framework proposed by Sickles (2005).

${ }^{9}$ In particular Kumbhakar (1991) proposed a three-stage estimation procedure to solve the model with time- and firm-specific effects, Polachek and Yoon (1996) estimated a panel data frontier model with firm dummies and Heshmati (1998) used a two-step procedure in a random-effect framework to separate the firm-specific effects from efficiency differences.

${ }^{10}$ See Saal, Parker and Weyman-Jones (2007), Farsi, Filippini and Greene (2006), Farsi, Filippini and Kuenzle (2006) and Farsi, Filippini and Greene (2005) for applications in water distribution, electricity networks, bus transport and railroads respectively.
} 
ing inefficiency and a normal random variable that captures the statistical noise. In this study, we used the true random effect model, mainly because the numerical solution of the fixed effects model was cumbersome and did not converge to sensible results for the estimates of inefficiencies and individual intercepts. In order to provide a basis for comparing the results, three other models namely, Pitt and Lee (1981), Battese and Coelli (1992) and a GLS model in line with Schmidt and Sickles (1984) have also been considered. These models will be described in the next section.

\section{Data and model specification}

The data used in this study includes financial and technical information from a sample of electricity, natural gas and water distribution companies that have operated in Switzerland between 1997 and 2005. The data have been mainly collected from the annual reports. Information on the size of the firm's distribution area is from the “Arealstatistik 2002” published by the Federal Statistical Office and the "Preisüberwacher”. The original data set covers about 90 companies covering about $42 \%$ of total electricity, $67 \%$ of total gas and $22 \%$ of total water distribution in Switzerland. That sample includes multi-utility firms as well as specialized companies in electricity, gas and water sectors and several double-output utilities, but excludes companies with more than $10 \%$ self-generation of total electricity distribution.

Since the focus of this study is on the horizontal integrated multi-utilities, we focused on a sub-sample of the data used by Farsi, Fetz and Filippini (2008), ${ }^{11}$ including observations from 34 companies. Moreover, as pointed out by Saal and Parker (2006) assuming a similar cost frontier among multi-output companies and specialized utilities is not a realistic assumption and might cause considerable distortion in efficiency estimates and ranking. Because the primary purpose of this analysis is the

\footnotetext{
${ }^{11}$ In that study we analyzed the economies of scope and scale in Swiss multi-utilities using a quadratic cost function without performing a frontier analysis. In contrast with the present study, the estimation of the economies of scope requires data from the integrated multi-utilities as well as specialized distributors. Pooling the data across different types of utilities is not appropriate for a benchmarking analysis that relies on comparing comparable companies.
} 
estimation of cost-efficiency, we did not pool the multi-utilities with specialized companies.

The final sample used in this analysis consists of an unbalanced panel data set including observations from 34 multi-utilities during the nine-year period spanning from 1997 to 2005 . The sample represents about $60 \%$ of the integrated multi-utilities in Switzerland. According to our estimates based on the available information, the multi-utilities included in the sample cover about half of the national electricity and gas consumption provided by multi-utilities and about a fifth of the water distributed by multi-utilities. Overall, these companies cover approximately $13 \%$ of electricity, $38 \%$ of gas and $14 \%$ of water distribution in the entire country.

The model specification is based on a cost function with three outputs namely, the distributed electricity, gas and water and four input factors that is, labor and capital as well as the electricity and gas inputs. As in Sing (1987) customer density is introduced as a service area characteristic. This variable should capture, at least partially, the cost impact of the heterogeneity of the service area of the companies. In fact, differences in networks and environments influence the production process and therefore the costs. Obviously, the heterogeneity of the service area cannot be summarized into a single variable. However, the available data do not allow for any other environmental or network characteristic that is reasonably independent of the included explanatory variables. Given the risk of multicollineraity in the translog function, especially in the second-order terms, we preferred to retain a relatively simple specification. ${ }^{12}$ Thus, some of these characteristics are inevitably omitted from the cost function specification. As we see later these omitted factors are represented by firmspecific stochastic components in the adopted panel data econometric models.

\footnotetext{
${ }^{12}$ In a preliminary analysis we introduced some other network characteristics such as the total length of the networks (gas, electricity, water), the share of the individual network on total network, the number of customers and the service area size. Unfortunately, we experienced numerical problems such as nonconvergence or degeneracy of one of the stochastic components. We recognize that the adopted specification only partly accounts for the observed heterogeneity.
} 
Assuming that the technology is convex and the firm minimizes cost, the adopted total cost function can be written as:

$$
C=C\left(q^{(1)}, q^{(2)}, q^{(3)}, r, w^{(0)}, w^{(1)}, w^{(2)}, w^{(3)}, D_{t}\right)
$$

where $C$ represents total costs; $q^{(1)}, q^{(2)}$ and $q^{(3)}$ are respectively the distributed electricity, gas and water during the year, $w^{(0)}, w^{(1)}, w^{(2)}$ and $w^{(3)}$ are respectively the input factor prices for capital and labor services and the purchased electricity and gas; $r$ is the customer density ${ }^{13}$ measured by the number of customers in the electricity sector divided by the size of the service area measured in square kilometers; and $D_{t}$ is a vector of year dummies that represent technical change and other year-to-year variations with the first year of the sample (1997) as the omitted category. The technical change is assumed to be neutral with respect to cost minimizing input ratios, that is, it is represented by a cost shift that does not alter the optimal input bundles. ${ }^{14}$

An important implication of the above specification is that the estimated economies of scale are based on the usual assumption (in line with Caves et al., 1981) that any change in the production scale entails a uniform proportional change in all outputs and network characteristics, thus retaining the same ratios in particular the same customer density. This assumption is consistent with many policy applications such as the economic assessment of mergers and acquisitions and the extension of local monopolists to new areas. However, the potential synergies could be understated in other cases such as the assessment of side-by-side competition, where considerable

\footnotetext{
${ }^{13}$ For the computation of the costumer density we used the number of costumers in the electricity sector. We have chosen the electricity sector, because is the sector with the largest number of costumers. This measure should approximated the customer density in all services (gas, water, electricity). Of course, we are aware that the inclusion of three different variables regarding the customer density would have been more appropriate. However, due to multicollinearity problem we were not able to adopt a richer model specification.

${ }^{14}$ As we will see later our regressions suggest that the time-variation of costs is not linear. These variations can be explained by many unobserved factors (such as changes in labor contracts or seasonal composition of the demand) that change uniformly across companies.
} 
economies might also be achieved by increasing the density, namely the economies of density. ${ }^{15}$ Unfortunately, the sample's independent variations in networks and outputs do not seem to be sufficient for a meaningful empirical distinction between the economies of scale and the economies of density. In fact, our preliminary analyses with several alternative specifications particularly, models including the size of the service area and/or the number of customers, indicated certain discrepancy in the signs and statistical significance of output coefficients, which can be explained by multicollinearity problems due to the strong correlation of output variables with those characteristics.

The variables for the cost function specification were constructed as follows. Total costs $(C)$ are calculated as the total firm's expenditures in a given year. The outputs $q^{(m)}$ are measured by the total quantity delivered to the customers. The measurement units are GWh for electricity and gas and million cubic meters for water. Input prices are defined as factor expenditures per factor unit.

The capital price is the most difficult variable to measure because capital is purchased in one time period but delivers a flow of services over subsequent time periods. Moreover, in multi-utilities the capital intensity varies between activities (gas, electricity, water). From a theoretical point of view the best approach is to apply the methodology proposed by Jorgenson (1963) which is based on the measurement of capital stock by the capital inventory method and on a definition of capital price based on the relationship between the acquisition price of new capital goods and the present value of all future services received. Unfortunately, no data is available which would allow the application of this approach for each individual sector. Therefore, following Friedlaender and Chiang (1983), we used the residual approach for estimating the capital prices. The residual costs are specified as the company's total costs net of labor expenditures and purchases of electricity and natural gas.

\footnotetext{
${ }^{15}$ The economies of output (customer) density describe the effects of changes in output (number of customers) keeping all other network characteristics fixed (Caves et al., 1985; 1984). As illustrated in Farsi, Filippini and Kuenzle (2007, 2006), the economies of density are usually greater than the economies of scale.
} 
Capital price for each network is obtained by dividing the residual costs by the capital stock measured by the network length. The overall capital price $\left(w^{(0)}\right)$ is then calculated as a weighted average of capital prices for each of the three sectors namely, electricity, natural gas and water. The weights, similar to Fraquelli, Piacenza et al. (2004), are proportional to the share of the residual costs in each sector out of the multi-utlity's total residual costs. Labor price $\left(w^{(1)}\right)$ is defined as the ratio of annual labor costs to the total number of employees in terms of full time equivalent worker. In a few cases in which the full time equivalent was not available, in order to avoid the underestimation of labor price due to part-time employees, we considered a correction based on the mean labor price values within the same canton. The electricity and gas prices $\left(w^{(2)}, w^{(3)}\right)$ are defined as the expenditures of purchasing the input factors divided by the amount purchased (in MWh).

Table 1 provides a descriptive summary of the variables included in the model. All the costs and prices are adjusted for inflation using consumer price index and are measured in year 2000 Swiss Francs (CHF). As can be seen in the table, the sample shows a considerable variation in costs and all three outputs. 
Table 1: Descriptive statistics (237 observations from 34 companies)

\begin{tabular}{llcccc}
\hline Variable & Min. & Median & Mean & Max. \\
\hline$C$ & $\begin{array}{l}\text { Total costs } \\
\text { (CHF Mio.) }\end{array}$ & 11.20 & 41.10 & 77.60 & 503.00 \\
$q^{(1)}$ & $\begin{array}{l}\text { Electricity distri- } \\
\text { bution (GWh) }\end{array}$ & 38.78 & 126.89 & 293.23 & $2^{\prime} 023.59$ \\
$q^{(2)}$ & $\begin{array}{l}\text { Gas distribution } \\
\text { (GWh) }\end{array}$ & 28.82 & 226.34 & 512.60 & $4^{\prime 2} 294.20$ \\
$q^{(3)}$ & $\begin{array}{l}\text { Water distribution } \\
\left.\text { (Mio. m }{ }^{3}\right)\end{array}$ & 0.78 & 2.45 & 5.28 & 33.35 \\
$r$ & $\begin{array}{l}\text { Customer density } \\
\left.\text { (customer/ km }{ }^{2}\right)\end{array}$ & 44.35 & 298.33 & 387.57 & $1^{\prime} 554.09$ \\
$w^{(0)}$ & $\begin{array}{l}\text { Capital price } \\
\text { (CHF/ km) }\end{array}$ & $11^{\prime} 853$ & $31^{\prime} 167$ & $38 ' 385$ & $2344^{\prime} 796$ \\
$w^{(1)}$ & $\begin{array}{l}\text { Labor price } \\
\text { (CHF/ employee) }\end{array}$ & $77^{\prime} 789$ & $1066^{\prime} 466$ & $107 ' 851$ & $1466^{\prime} 816$ \\
$w^{(2)}$ & $\begin{array}{l}\text { Electricity price } \\
\text { (CHF/ MWh) }\end{array}$ & 44.6 & 107.4 & 105.9 & 163.5 \\
$w^{(3)}$ & $\begin{array}{l}\text { Gas price } \\
\text { (CHF/ MWh) }\end{array}$ & 16.6 & 28.4 & 29.3 & 63.2 \\
\hline
\end{tabular}

Following Christensen et al. (1973) we use a translog model which is probably the most widely used functional form in empirical studies of cost and production functions. ${ }^{16}$ This flexible functional form is a local, second-order approximation to any arbitrary cost function. The approximation point is usually set at the sample mean or median. Here the approximation point has been set at the sample median. Compared to the mean, the median values are less affected by outlier values. The translog form does not impose any restrictions on the elasticity of substitution and allows the economies of scale to vary with the output level. In order to avoid the excessive number of parameters we have considered a homothetic cost function in which the interac-

\footnotetext{
${ }^{16}$ See Caves et al. (1980) on the advantages of translog form in multiproduct settings and Griffin et al. (1987) for a discussion of the criteria used for the choice of the functional form.
} 
tion terms between input price variables and output variables are excluded. ${ }^{17}$ This brings about another assumption namely that marginal costs particularly cost complementarities and scale elasticities depend only upon the technological characteristics of the production, thus being independent of input prices. This is a valid assumption insofar as the input prices remain in a reasonable range, especially because the potential changes in the shape of the cost function can easily be dominated by other approximations entailed by the functional form.

It is generally assumed that the cost function is the result of cost minimization given input prices and output and should therefore satisfy certain properties. Mainly, this function must be non-decreasing in output and non-decreasing, concave and linearly homogeneous in input prices (Cornes, 1992). We imposed the latter condition by normalization of prices namely, by dividing the costs and all factor prices by one common factor price referred to as numeraire ( $c f$. Farsi, Fetz et al., 2007b; Featherstone and Moss, 1994; Jara-Diaz, Martinez-Budria et al., 2003). Here we used the capital price as the numeraire. The remaining conditions can be tested based on the estimation results.

The general econometric specification of the cost function in (3) can be written as:

$$
\begin{aligned}
\ln \left(\frac{C_{i t}}{w_{i t}^{(0)}}\right) & =\sum_{m} \alpha^{m} \ln q_{i t}^{(m)}+\alpha^{r} \ln r_{i t}+\sum_{k} \beta^{k} \ln \frac{w_{i t}^{(k)}}{w_{i t}^{(0)}}+\frac{1}{2} \sum_{m} \alpha^{m m}\left(\ln q_{i t}^{(m)}\right)^{2} \\
& +\sum_{m(m \neq n)} \sum_{n} \alpha^{m n} \ln q_{i t}^{(m)} \ln q_{i t}^{(n)}+\frac{1}{2} \alpha^{r r}\left(\ln r_{i t}\right)^{2}+\sum_{m} \alpha^{r m} \ln q_{i t}^{(m)} \ln r_{i t} \\
& +\frac{1}{2} \sum_{k} \beta^{k k}\left(\ln \frac{w_{i t}^{(k)}}{w_{i t}^{(0)}}\right)^{2}+\sum_{k(k \neq l)} \sum_{l} \beta^{k l} \ln \frac{w_{i t}^{(k)}}{w_{i t}^{(0)}} \ln \frac{w_{i t}^{(l)}}{w_{i t}^{(0)}} \\
& +\sum_{t} \delta^{t} D_{t}+\alpha^{0}+\alpha_{i}+u_{i t}+v_{i t},
\end{aligned}
$$

\footnotetext{
${ }^{17}$ We evaluated the possibility of applying a non-homothetic translog form. However, the relatively large number of parameters created certain numerical problems in some of the econometric models, especially the true random effects model that requires a simulated likelihood maximization method. This is perhaps related to problems due to the model's over-identification and perhaps multicollinearity as suggested by the lack of significance and counter-intuitive signs for some of the main variables.
} 
where subscripts $i$ and $t$ denote the company and year respectively; the parameters $\alpha^{m}, \beta^{k}, \alpha^{m n}, \beta^{k l}, \delta^{t}$ and $\alpha^{0} \quad(m, n, k, l=1,2,3 ; t=1998, \ldots, 2005)$ are the regression coefficients to be estimated; and all second-order parameters $\alpha^{n m}$ and $\beta^{k l}$, satisfy the symmetry conditions $\left(\beta^{k l}=\beta^{l k} ; \alpha^{m n}=\alpha^{n m}\right)$; $\alpha_{i}$ is a firm-specific effect; $u_{i t}$ is an asymmetric stochastic component term that captures the time-variant inefficiency and $v_{i t}$ is a symmetric term representing random noise and statistical errors.

We consider four variations of the above model. These models are summarized in Table 2. The first model (Model $I$ ) is a random effects model in line with Schmidt and Sickles (1984), estimated using the Generalized Least Squares (GLS) method. Model II is a random effects model proposed by Pitt and Lee (1981) estimated using the maximum likelihood method. In line with Kumbhakar and Lovell (2000) we will refer to this model as the maximum likelihood (ML) model. Model III is based on Battese and Coelli (1992) with an exponential decay function for inefficiency term. ${ }^{18}$ In both models $I$ and $I I$, it is assumed that all the unobserved differences across firms that do not vary over time are related to inefficiency. Model III relaxes the time-invariance by imposing a deterministic form of evolution that is uniform among all companies. In all three models, all the unobserved differences that cannot be captured by the random noise $\left(v_{i t}\right)$ are assumed to be due to inefficiency.

As we have seen in the previous section this could be a restrictive assumption in network industries especially in multi-utilities, which might entail a considerable cost variation through unobserved factors that vary from one network to another but are more or less constant over time and cannot be changed by the management. This implies that in these cases some of the unobserved heterogeneity, for instance, the complexity of the distribution network that is mainly determined by the topology of the service area, can be identified as inefficiency. In contrast, Model $I V$, the 'true random effects' specification proposed by Greene (2005a,b), allows for a separate sto-

\footnotetext{
${ }^{18}$ Battese and Coelli $(1992,1995)$ have proposed variations of this model with different distributions for $u_{i}$, including truncated normal distribution. In this study we assume a half-normal distribution.
} 
chastic term that captures the time-invariant unobserved heterogeneity. This model is estimated using Simulated Maximum Likelihood (SML) method. ${ }^{19}$

Table 2: Econometric specifications of the stochastic cost frontier

\begin{tabular}{|c|c|c|c|c|}
\hline Stochastic term & $\begin{array}{c}\text { Model I } \\
\text { GLS } \\
\text { (Schmidt and } \\
\text { Sickles, 1984) }\end{array}$ & $\begin{array}{c}\text { Model II } \\
\text { ML } \\
\text { (Pitt and Lee, 1981) }\end{array}$ & $\begin{array}{c}\text { Model II } \\
\text { ML } \\
\text { (Battese and Coelli, } \\
\text { 1992) }\end{array}$ & $\begin{array}{l}\text { Model IV } \\
\text { True RE } \\
\text { (Greene, } \\
\text { 2005a,b) }\end{array}$ \\
\hline $\begin{array}{l}\text { Firm-specific } \\
\text { effect } \alpha_{i}\end{array}$ & $\alpha_{i} \sim \operatorname{iid}\left(0, \sigma_{\alpha}^{2}\right)$ & $\alpha_{i} \sim \mathrm{N}^{+}\left(0, \sigma_{\alpha}^{2}\right)$ & 0 & $\alpha_{i} \sim \mathrm{N}\left(0, \sigma_{\alpha}^{2}\right)$ \\
\hline $\begin{array}{l}\text { Time-varying } \\
\text { inefficiency } u_{i t}\end{array}$ & 0 & 0 & $\begin{array}{l}u_{i t}= \\
u_{i} \exp \left\{-\eta\left(t-T_{i}\right)\right\} \\
u_{i} \sim \mathrm{N}^{+}\left(0, \sigma_{u}^{2}\right)\end{array}$ & $u_{i t} \sim \mathrm{N}^{+}\left(0, \sigma_{u}^{2}\right)$ \\
\hline Random noise $v_{i t}$ & $v_{i t} \sim \operatorname{iid}\left(0, \sigma_{v}^{2}\right)$ & $v_{i t} \sim \mathrm{N}\left(0, \sigma_{v}^{2}\right)$ & $v_{i t} \sim \mathrm{N}\left(0, \sigma_{v}^{2}\right)$ & $v_{i t} \sim \mathrm{N}\left(0, \sigma_{v}{ }^{2}\right)$ \\
\hline $\begin{array}{l}\text { Inefficiency es- } \\
\text { timate }\end{array}$ & $\hat{\alpha}_{i}-\min \left\{\hat{\alpha}_{i}\right\}$ & $\begin{array}{l}\mathrm{E}\left[\alpha_{i} \mid \hat{\omega}_{i 1}, \hat{\omega}_{i 2}, \ldots\right] \\
\text { with } \omega_{i t}=\alpha_{i}+v_{i t}\end{array}$ & $\begin{array}{l}\mathrm{E}\left[u_{i t} \mid \hat{\varepsilon}_{i t}\right] \\
\text { with } \varepsilon_{i t}=u_{i t}+v_{i t}\end{array}$ & $\begin{array}{l}\mathrm{E}\left[u_{i t} \mid \hat{r}_{i t}\right] \\
\text { with } \\
r_{i t}=\alpha_{i}+u_{i t}+v_{i t}\end{array}$ \\
\hline
\end{tabular}

- The hat symbol $\wedge$ is used to indicate the post-estimation predicted value.

- Model $I$ : The inefficiency is estimated compared to the 'best-performance' company with the minimum value of $\alpha_{i}$.

- Model II: The inefficiency is estimated based on Jondrow et al. (1982).

- $\quad$ Model III: $\mathrm{E}\left[u_{i t} \mid \hat{\varepsilon}_{i t}\right]=\mathrm{E}\left[u_{i} \mid \hat{\varepsilon}_{i 1}, \hat{\varepsilon}_{i 2}, \ldots, \hat{\varepsilon}_{i T}\right] \exp \left\{-\eta\left(t-T_{i}\right)\right\} ; T_{i}$ denotes the period corresponding with the last observation for company $i$. In this model company $i$ starts with an initial level of inefficiency of $u_{i 0}=u_{i} \exp \left(\eta T_{i}\right)$, that declines over time with an exponential rate of $\exp (-\eta)$ per period and reaches $u_{i}$ at the end of the sample period.

- Model IV: The conditional expectation of inefficiency is calculated by Monte Carlo simulations (Green, 2005b).

Regarding the distribution assumptions, excepting the GLS model, the inefficiency term is assumed to follow a half-normal distribution which is obtained by a

\footnotetext{
${ }^{19}$ We used quasi-random Halton draws to minimize the potential sensitivity of the results to simulation process. Number of draws has been fixed to 1000 . Our sensitivity analysis using several options suggested that the estimation results are not sensitive when the number of draws is higher than a few hundred.
} 
zero-mean normal distribution truncated at zero. Dating back to the original frontier models (Aigner et al., 1977; Meeusen and van der Broek, 1997), this assumption implies that full efficiency is the most frequent outcome located at the mode of the distribution. Unlike the GLS model that is based on a single best performance, the halfnormal distribution provides a relatively solid benchmark performance observed in a relatively large number of cases. Moreover, consistent with the economic theory, that predicts the prevalence of rational and cost-minimizing behavior this distribution implies that higher levels of inefficiency have lower incidence.

All the adopted models assume that the stochastic terms namely, costefficiency and unobserved heterogeneity are independent from each other and are both uncorrelated with the explanatory variables included in the model. There are several methods to relax these assumptions. For instance the correlation between firm-specific effects and explanatory variables can be allowed by Mundlak’s specification (Farsi, Filippini and Greene, 2005; Farsi, Filippini and Kuenzle; 2005) or the impact of explanatory variables on efficiency can be modeled by specifying the truncation point of the normal distribution as a function of observed factors (Kumbhakar et al., 1991; Battese and Coelli, 1995) or as a general functional form (Wang and Schmidt, 2002). However, such elaborations can only be achieved through more complicated and often arbitrary assumptions thus compromising the clarity of the original assumptions.

\section{Empirical results}

Table 3 lists the regression results of the cost frontier analysis, using the four alternative models as presented in Equation (4) and Table 2. All the estimated coefficients of the first-order terms have the expected signs and are statistically significant across all models. Given that all the variables except the dummy variables are in logarithmic form, these coefficients can be directly interpreted as elasticities. The coefficients of first-order output variables $\left(\alpha^{1}, \alpha^{2}, \alpha^{3}\right)$ represent the cost elasticities with respect to the corresponding outputs at the sample median. These coefficients indicate that the marginal costs of electricity distribution are considerably higher than those of natural gas, which in turn are substantially greater than those of water distribution. 
Table 3: Estimation results

\begin{tabular}{|c|c|c|c|c|c|c|c|c|}
\hline \multirow[b]{2}{*}{$\alpha^{1}$ (Electricity output) } & \multicolumn{2}{|c|}{$\begin{array}{c}\text { Model I } \\
\text { GLS (Schmidt-Sickles) }\end{array}$} & \multicolumn{2}{|c|}{$\begin{array}{c}\text { Model II } \\
\text { ML (Pitt-Lee) } \\
\end{array}$} & \multicolumn{2}{|c|}{$\begin{array}{c}\text { Model III } \\
\text { ML (Battese-Coelli) } \\
\end{array}$} & \multicolumn{2}{|c|}{$\begin{array}{c}\text { Model IV } \\
\text { True RE (Greene) } \\
\end{array}$} \\
\hline & 0.505 ** & $(.053)$ & 0.460 ** & $(.069)$ & $0.418^{* *}$ & $(.063)$ & $0.527^{* *}$ & $(.020)$ \\
\hline$\alpha^{2}$ (Gas output) & 0.317 ** & $(.032)$ & 0.298 ** & $(.041)$ & $0.245^{\star *}$ & $(.045)$ & 0.258 ** & $(.012)$ \\
\hline$\alpha^{3}$ (Water output) & 0.092 ** & $(.039)$ & 0.178 ** & $(.053)$ & $0.212^{* \star}$ & $(.047)$ & 0.146 ** & $(.015)$ \\
\hline$\alpha^{r}$ (Customer density & 0.064 ** & $(.027)$ & 0.043 & $(.038)$ & 0.026 & $(.037)$ & 0.007 & $(.009)$ \\
\hline$\beta^{1}$ (Labor price) & 0.242 ** & $(.057)$ & 0.229 ** & $(.054)$ & 0.236 ** & $(.058)$ & 0.201 ** & $(.027)$ \\
\hline$\beta^{2}$ (Electricity price & 0.326 ** & $(.059)$ & 0.317 ** & $(.051)$ & $0.333^{* *}$ & $(.052)$ & $0.370^{* *}$ & $(.033)$ \\
\hline$\beta^{3}$ (Gas price) & 0.234 ** & $(.043)$ & 0.243 ** & $(.039)$ & 0.223 ** & $(.038)$ & $0.215^{* *}$ & $(.024)$ \\
\hline$\alpha^{11}$ & 0.646 ** & $(.197)$ & 0.368 * & $(.221)$ & 0.218 & $(.193)$ & 0.231 ** & $(.086)$ \\
\hline$\alpha^{22}$ & 0.234 ** & $(.055)$ & 0.154 * & $(.080)$ & 0.067 & $(.071)$ & 0.093 ** & $(.023)$ \\
\hline$\alpha^{33}$ & 0.287 ** & $(.141)$ & 0.042 & $(.176)$ & 0.186 & $(.167)$ & 0.089 * & $(.052)$ \\
\hline$\alpha^{r r}$ & 0.019 & $(.061)$ & -0.063 & $(.095)$ & $-0.233 * \star$ & $(.089)$ & -0.146 ** & $(.026)$ \\
\hline$\alpha^{12}$ & $-0.273 * \star$ & $(.086)$ & -0.182 * & $(.105)$ & -0.048 & $(.091)$ & $-0.099 * *$ & $(.041)$ \\
\hline$\alpha^{13}$ & -0.327 ** & $(.149)$ & -0.124 & $(.158)$ & -0.214 & $(.148)$ & -0.133 ** & $(.058)$ \\
\hline$\alpha^{1 r}$ & $-0.215^{\star *}$ & $(.070)$ & -0.220 ** & $(.097)$ & 0.074 & $(.104)$ & -0.119 ** & $(.030)$ \\
\hline$\alpha^{23}$ & -0.002 & $(.059)$ & 0.049 & $(.072)$ & 0.051 & $(.068)$ & 0.037 & $(.026)$ \\
\hline$\alpha^{2 r}$ & 0.123 ** & $(.059)$ & -0.002 & $(.079)$ & -0.147 * & $(.080)$ & $-0.065^{\text {** }}$ & $(.027)$ \\
\hline$\alpha^{3 r}$ & 0.085 * & $(.050)$ & 0.120 & $(.081)$ & 0.104 & $(.076)$ & 0.122 ** & $(.020)$ \\
\hline$\beta^{11}$ & 0.419 & $(.279)$ & -0.031 & $(.270)$ & 0.051 & $(.248)$ & 0.384 ** & $(.121)$ \\
\hline$\beta^{22}$ & 0.695 ** & $(.205)$ & 0.524 ** & $(.172)$ & $0.565^{* *}$ & $(.167)$ & $0.758^{* \star}$ & $(.110)$ \\
\hline$\beta^{33}$ & $-0.243 * *$ & $(.120)$ & -0.291 ** & $(.106)$ & $-0.278 * \star$ & $(.110)$ & -0.217 ** & $(.108)$ \\
\hline$\beta^{12}$ & -0.701 ** & $(.221)$ & -0.419 ** & $(.197)$ & -0.460 ** & $(.189)$ & $-0.724^{\star \star}$ & $(.102)$ \\
\hline$\beta^{13}$ & $0.294^{\star \star}$ & $(.147)$ & 0.422 ** & $(.137)$ & $0.386^{\star *}$ & $(.136)$ & $0.351^{\star *}$ & $(.096)$ \\
\hline$\beta^{23}$ & -0.096 & $(.135)$ & -0.154 & $(.118)$ & -0.156 & $(.115)$ & -0.136 & $(.092)$ \\
\hline$\delta^{1998}$ & -0.004 & $(.019)$ & -0.005 & $(.015)$ & 0.011 & $(.016)$ & -0.005 & $(.032)$ \\
\hline$\delta^{1999}$ & -0.003 & $(.020)$ & -0.002 & $(.016)$ & 0.028 & $(.019)$ & -0.005 & $(.021)$ \\
\hline$\delta^{2000}$ & -0.015 & $(.021)$ & -0.013 & $(.018)$ & 0.035 & $(.024)$ & -0.006 & $(.025)$ \\
\hline$\delta^{2001}$ & -0.014 & $(.023)$ & -0.015 & $(.020)$ & 0.049 * & $(.029)$ & -0.012 & $(.022)$ \\
\hline$\delta^{2002}$ & $-0.037^{*}$ & $(.021)$ & -0.036 ** & $(.018)$ & 0.036 & $(.030)$ & -0.040 * & $(.022)$ \\
\hline$\delta^{2003}$ & $-0.041^{*}$ & $(.021)$ & $-0.044^{* *}$ & $(.018)$ & 0.039 & $(.033)$ & -0.039 * & $(.023)$ \\
\hline$\delta^{2004}$ & -0.064 ** & $(.023)$ & -0.069 ** & $(.020)$ & 0.032 & $(.038)$ & $-0.067^{\star \star}$ & $(.024)$ \\
\hline$\delta^{2005}$ & -0.059 ** & $(.026)$ & -0.065 ** & $(.023)$ & 0.046 & $(.043)$ & $-0.073^{* *}$ & $(.022)$ \\
\hline$\alpha^{0}$ & $7.164^{\star \star}$ & $(.029)$ & 6.989 ** & $(.032)$ & $6.917^{* *}$ & $(.046)$ & 7.120 ** & $(.019)$ \\
\hline$\sigma_{\alpha}$ & .053 & & 0.217 ** & $(.034)$ & & & $0.114 * *$ & $(.005)$ \\
\hline$\sigma_{u}$ & & & & & 0.210 ** & $(.039)$ & $0.081 * *$ & $(.030)$ \\
\hline$\sigma_{v}$ & .054 & & 0.054 ** & $(.003)$ & 0.052 ** & $(.003)$ & $0.024 * *$ & $(.006)$ \\
\hline$\eta$ & & & & & 0.048 ** & $(.015)$ & & \\
\hline $\log L$ & Not Applicable (R & $\left.\mathrm{R}^{2}=0.982\right)$ & 296.785 & & 299.355 & & 303.786 & \\
\hline
\end{tabular}

** and * refer to $5 \%$ and $10 \%$ significance levels respectively. Standard errors are given in parentheses. 
The inverse of the sum of the three coefficients of first-order output variables represent a measure of global economies of scale at the sample median. The results indicate that this value is significantly greater than one suggesting global scale economies in the majority of the companies included in the sample. Many of the secondorder terms are also statistically significant, implying that the assumption of constant elasticities is unrealistic. The coefficients of the squared output terms $\left(\alpha^{11}, \alpha^{22}, \alpha^{33}\right)$ are positive and mostly significant across all models. This suggests that a marginal increase in a given output increases the cost elasticity of that output. Therefore, as expected, the (product-specific) economies of scale are decreasing in output.

As we see in Table 3 the output cross-interaction terms $\left(\alpha^{12}, \alpha^{13}, \alpha^{23}\right)$ are mostly negative across the models. In particular, the cross effect between electricity and other two outputs (natural gas and water), is statistically significant, suggesting lower marginal costs in one sector as a result of increasing output in the other sector. The results show however that the cost complementarity between gas and water outputs $\left(\alpha^{23}\right)$ is not statistically significant. This lack of significance could be explained by the relatively low marginal cost of both outputs which cause statistical problems in detecting the second-order decreasing effect.

As for the effect of customer density, the results show that the first order term is positive but statistically insignificant in most models. This suggests that the effect at the median company is probably not important. However, the mostly negative coefficient of the square term $\left(\alpha^{r r}\right)$ suggests that higher densities could have a decreasing effect on costs. At first impression, this can be considered as counter-intuitive because increasing the customer density may be economical in low-density areas, but could create extra costs in congested areas. However, the statistically significant interaction terms between customer density and outputs, suggest that the density has a strongly non-linear effect depending on the output combination across the three services.

For instance the interaction term with electricity output $\left(\alpha^{1 r}\right)$ is mostly negative and significant, suggesting that the marginal cost of electricity output is lower in networks with higher customer density. This cannot be said for gas and water outputs. Especially the corresponding interaction term for water distribution $\left(\alpha^{3 r}\right)$ is mostly on the positive side, suggesting that an increase in customer density will increase the 
marginal cost of water distribution. These results can be related to different costs of network connection for various outputs, and also different amount of extra cables and pipes required for the provision of greater volumes of electricity, gas and water, depending on the actual customer density. For instance, in a dense and crowded area providing more electricity might be handled easier than a considerable increase in gas and water output. Moreover, connection of new customers to electricity networks is probably less costly than that of water and gas distribution networks.

The coefficients of the first-order terms of input prices are an indicator of the share of each factor price at the sample median. ${ }^{20}$ Based on the regression results, the shares of labor, electricity and gas inputs respectively amount to about 22, 33 and 23 percent of the total costs. These numbers are comparable to the sample mean of the observed factor shares which is 12,35 and 17 percent of the company's total costs, respectively for labor, electricity and gas inputs. As we see the share of electricity and gas expenses are quite close the average observed values. The remaining costs have been considered as 'capital' costs that are 36 percent on average, but about 22 percent from the regression results. Therefore in the model, the share of labor costs is overstated compared to that of the residual capital costs.

We explored if the estimated cost functions satisfy the theoretical properties implied by cost-minimization. As shown by the positive coefficients of the first order terms (Table 3), all the estimated cost functions are non-decreasing in output and input prices at the approximation point (sample median). However, our calculations showed that the Hessian matrix defined by the second derivatives of the translog cost function with respect to log of input prices, is not negative semi-definite. The violation of this necessary condition ${ }^{21}$ for concavity might be considered as an indication

\footnotetext{
${ }^{20}$ Note that in translog form, any statement about sample points other than the approximation point (here, sample median), should consider the second-order terms in addition to the main effects.

${ }^{21}$ As pointed out by Diewert and Wales (1987), even with a negative semi-definite Hessian matrix for the translog cost function, the costs might be concave with respect to input prices. So applying such a condition on the coefficient matrix of a translog cost function is too strong for concavity in input prices.
} 
that the concavity in input prices is not satisfied. This result can be explained by the fact that these local monopolies do not face any competitive pressure, ${ }^{22}$ but also that the multi-utilities are not as sensitive to price changes as the textbook economic theory might predict. Theoretically the companies are expected to substitute labor with capital or capital with energy in response to changes in the relative prices. However, in practice these substitutions are not feasible in many cases. For instance if the relative price of electricity to gas increases, the companies cannot substitute electricity input with gas input, because these inputs are mainly determined by the demand side.

In any case, even if we consider the lack of concavity in input prices as an indication that the companies do not fully minimize their costs the estimated cost functions can be useful to study the marginal effects of different factors on costs and also to compare the companies’ performance. In such cases, as pointed out by Bös (1986) and Breyer (1987), functions based on cost optimization can still be used as 'behavioral' cost functions and can be helpful in studying the firms' behavior. Moreover, we should keep in mind that we are estimating a cost frontier function, which allow the possibility that some companies do not minimize their costs.

The estimates of inefficiency scores obtained from the four models are summarized in Table 4. As expected, compared to all other models, the True RE model's estimates provide generally lower inefficiency. According to this model the multiutilities have on average about 6 percent excess costs compared to the fully efficient production whereas the other models predict from 18 to 21 percent excess cost on average. The median inefficiency for the True RE model is about 5\%, while being about $20 \%$ for all other models. It should be noted that the True RE model's estimates do not include the persistent inefficiencies that might remain more or less constant over time. To the extent that there are certain sources of inefficiency that result in timeinvariant excess costs, the estimates of the True RE model should provide a reasonable lower bound for the companies' inefficiency. On the other hand, in all the three other models, it is assumed that all the time-invariant cost differences due to exoge-

\footnotetext{
${ }^{22}$ This explanation was duly pointed out to us by an anonymous referee.
} 
nous heterogeneity are accounted for by the observed explanatory variables included in the model, and whatever remains can be interpreted as inefficiency. Therefore, the overall estimates of inefficiency obtained from these models can be considered as a kind of upper bound for the actual level of inefficiency in the sector.

Table 4: Descriptive summary of inefficiency estimates

\begin{tabular}{|c|c|c|c|c|}
\hline & $\begin{array}{c}\text { Model I } \\
\text { GLS (Schmidt-Sickles) }\end{array}$ & $\begin{array}{c}\text { Model II } \\
\text { ML (Pitt-Lee) }\end{array}$ & $\begin{array}{c}\text { Model III } \\
\text { ML (Battese-Coelli) }\end{array}$ & $\begin{array}{c}\text { Model IV } \\
\text { True RE (Greene) }\end{array}$ \\
\hline Std. Deviation & 0.184 & 0.183 & 0.216 & 0.063 \\
Minimum & 0.079 & 0.119 & 0.143 & 0.043 \\
$1^{\text {st }}$ Quartile & 0.000 & 0.013 & 0.014 & 0.010 \\
Median & 0.202 & 0.060 & 0.075 & 0.031 \\
$3^{\text {rd }}$ Quartile & 0.251 & 0.207 & 0.214 & 0.050 \\
Maximum & 0.303 & 0.401 & 0.693 & 0.277 \\
\hline
\end{tabular}

This interpretation of lower/upper bounds of inefficiency should be considered with special caution if applied to individual companies. The main problem is in distinguishing the persistent inefficiencies from external heterogeneity, thus from the excess costs that vary over time. The persistent inefficiencies might vary considerably from one company to another. From a regulator's point of view it is important to penalize the companies whose efficiency does not improve. Yet it is probably more important to make sure that the estimated excess costs are due to inefficiency rather than external factors beyond the management's control. A case-by-case analysis of individual inefficiency for a given company across several models and its variation over time can be quite informative.

The distribution of the inefficiency estimates in the sample is depicted in Figure 1. The distribution densities have been smoothed using Kernel density method. 
As seen in the figure the extent of inefficiency in the True RE model is considerably narrower than in other models. Moreover, the distribution of the GLS estimates suggest a negative skewness, which contradicts the usual assumption of positive skewness in cost-inefficiencies. Moreover, both Models II and III indicate a tendency toward a bimodal distribution, which goes against the underlying half-normal distribution assumption in these models. These peculiar patterns might be indicative that the econometric specification of the error term in the first three models could be insufficient to capture the inefficiencies in a coherent way. This can be explained by unobserved cost differences that are not due to inefficiency but to other external factors.

Figure 1: Distribution of inefficiency estimates

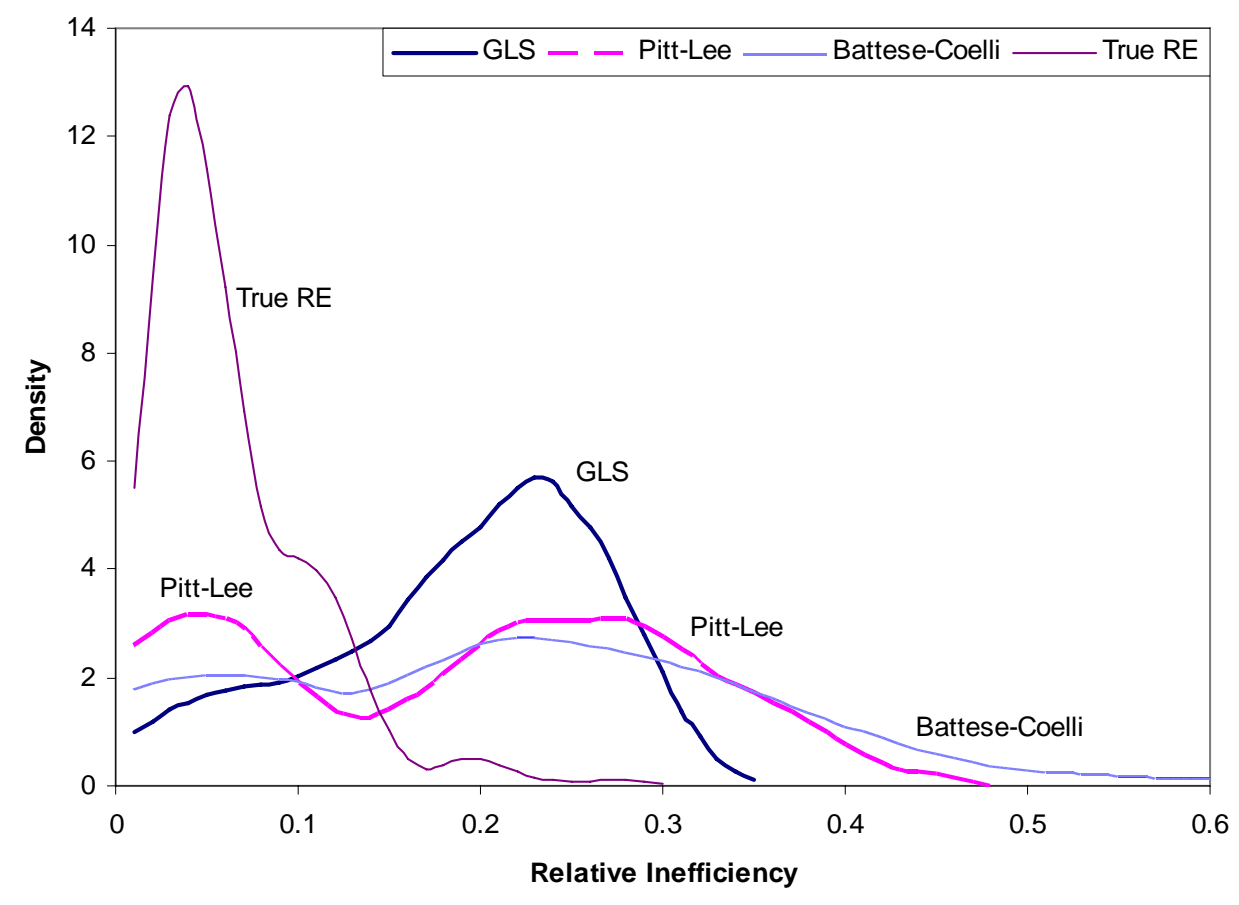

In order to explore if the efficiency estimates provide a consistent ranking pattern across different modes, we studied the correlation coefficients between these estimates. Table 5 provides the correlation matrix of inefficiency scores across the four models. The results suggest a high positive correlation among the first three models. There is however a relatively low correlation between each one of these models and 
the True RE model. The Spearman rank correlation matrix shows slightly lower correlation in general but confirms the above pattern namely low correlation between Model $I V$ and the other three models, and high correlation among the latter models. This result suggests that even if we are only interested in efficiency ranking rather than the numerical level of inefficiency, using the inadequate model can give a misleading ordering of individual companies.

\section{Table 5: Pearson correlation matrix between inefficiency estimates}

\begin{tabular}{|c|c|c|c|c|}
\hline & $\begin{array}{c}\text { Model I } \\
\text { GLS (Schmidt-Sickles) }\end{array}$ & $\begin{array}{c}\text { Model II } \\
\text { ML (Pitt-Lee) }\end{array}$ & $\begin{array}{c}\text { Model III } \\
\text { ML (Battese-Coelli) }\end{array}$ & $\begin{array}{c}\text { Model IV } \\
\text { True RE (Greene) }\end{array}$ \\
\hline I & 1 & $0.863^{* *}$ & $0.715^{* *}$ & $0.124^{*}$ \\
II & & 1 & $0.793^{* *}$ & $0.140^{* *}$ \\
III & & & 1 & $0.128^{* *}$ \\
\hline
\end{tabular}

** and * refer to $5 \%$ and $10 \%$ significance levels respectively.

Finally, it is important to note that in frontier models (such as models $I$ to $I I I$ ) that define the inefficiency based on time-invariant individual effects, any unexplained cost difference between companies is automatically associated with inefficiency. This explains why the spread of inefficiencies is narrower in Model IV (Figure 1). The latter model ensures that only asymmetric time-variant part of the excess costs is captured by the inefficiency term. That explains why this model is singled out in the correlation patterns shown in Table 5. Given the above discussions and the fact that the network industries are characterized by important spatial firm-specific characteristics that are only partially observable, we contend that the True RE model (Model IV) provides more reliable measures of inefficiency for multi-utilities. 


\section{Conclusions}

This study presents an empirical analysis of cost inefficiency in a sample of Swiss multi-utilities operating in the distribution of electricity, natural gas and water. The issues addressed in the study involve an important question related to the application of benchmarking analysis in incentive regulation schemes for multi-utilities. In general, the benchmarking of multiple-output companies is more complicated than in utilities with a similar output. Operating in several different sectors, multi-utilities hence are characterized by a strong unobserved heterogeneity that makes the measurement of their performance an important challenge for the regulators.

It is shown that the recent methodological developments in the estimation of cost frontier functions using panel data methods can be helpful to achieve more reliable estimates of inefficiency in presence of unobserved and omitted factors. The previous studies have used some of these methods in single-network distributors such as electricity and gas. However to our knowledge there is no reported empirical application in the multi-utility sector. The present analysis serves as a first illustration of the difficulties involved in the estimation of efficiency in multi-network utilities.

Using a translog cost function and several stochastic frontier models this analysis indicates the presence of unexploited global scale economies in the majority of the companies included in the sample. The efficiency estimates are sensitive to the econometric specification of unobserved factors through the model's stochastic components. While highlighting the potential problems in benchmarking multi-utilities, this study shows that adequate panel data models can be used to identify the inefficient companies and determine to certain extent, which part of their excess costs has been persistent and which part has varied over time.

Combining several frontier models also allows two types of inefficiency estimates: a "lower bound" estimate that includes only the transient part of the firm's excess costs assuming that all persistent cost differences are due to unobserved factors rather than poor efficiency performance, and an "upper bound" that associates all the firm-specific unaccounted cost differences to their productive efficiency and neglects the effect of external unobserved factors. Both estimates could be useful for the regulator, as they can use them to identify the companies that are persistently more costly 
than others and those that have high time-variant inefficiency. The regulator should perform further detailed and possibly case-by-case studies to assess to what extent the excessive costs of the former group can be associated with productive inefficiency and identify the potential external factors and peculiarities that might have caused such excessive costs.

\section{References}

Aigner, D., C. A. K. Lovell and P. Schmidt (1977). "Formulation and Estimation of Stochastic Frontier Production Function Models”, Journal of Econometrics, 6, 21-37.

Alvarez, A., C. Arias, and W. H. Greene (2004) 'Accounting for unobservables in production models: management and inefficiency.' Working Paper No. E2004/72, Centro de Estudios Andaluces, Spain.

Antonioli, B., and M. Filippini (2001) 'The Use of a Variable Cost Function in the Regulation of the Italian Water Industry’, Utilities Policy, 10 (3-4): 181-187.

Battese, G.E. and T. Coelli (1995). A model for technical inefficiency effects in a stochastic frontier production function for panel data. Empirical Econometrics, 20: 325-332.

Battese, George E. and Tim J. Coelli (1992). "Frontier production functions, technical efficiency and panel data: with application to paddy farmers in India”, Journal of Productivity Analysis, 3 (1): 153-169.

Battese, George E. and Tim J. Coelli (1988). "Prediction of firm-level technical efficiencies with a generalized frontier production function and panel data”, Journal of Econometrics, 38: 387-399.

Bös, D. (1986). Public Enterprise Economics, Amsterdam, North-Holland.

Breyer, Friedrich (1987). "The specification of a hospital cost function: A comment on the recent literature”, Journal of Health Economics, 6 (1987): 147-157.

Casarin, A. A. (2007). 'Efficient industry configurations in downstream gas markets. An empirical assessment', Energy Economics 29: 312-328.

Caves, Douglas W., L. R. Christensen, M. W. Tretheway, and R. J. Windle (1985) 'Network effects and the measurement of returns to scale and density for U.S. railroads', in Analytical Studies in Transpot Economics, editor. A. F. Daugherty, Cambridge University Press, pp. 97-120.

Caves, D. W., L. R. Christensen, and M. W. Tretheway (1984): "Economies of Density versus Economies of Scale: Why Trunk and Local Service Airline Costs Differ”. Rand Journal of Economics, 15 (4): 471-489. 
Caves, W. C., L. R. Christensen and J. A. Swanson (1981). "Productivity growth, scale economies, and capacity utilization in U.S. railroads, 1955-74”, American Economic Review, 71 (5): 994-1002.

Caves, D. W., L. R. Christensen and M. W. Tretheway (1980). "Flexible Cost Functions for Multiproduct Firms." Review of Economics and Statistics 62(3): 47781.

Chambers, R. G. (1988): Applied Production Analysis: A Dual Approach, Cambridge University Press.

Christensen, L. R., D. W. Jorgenson, L. J. Lau (1973): 'Transcendental Logarithmic Production Frontiers', Review of Economics and Statistics, 55(1): 28-45.

Coelli, T., D. S. P. Rao, and G. E. Battese (2005) An Introduction to Efficiency and Productivity Analysis, $2^{\text {nd }}$ edition, Springer Verlag.

Cornes, R. (1992). Duality and Modern Economics, Cambridge University Press.

Crouch, M. (2007). 'Investment under RPI-X: Practical experience with an incentive compatible approach in the GB electricity distribution sector', Utilities Policy, 14: 240-244.

Debreu, G. (1951). 'The Coefficient of Resource Utilization', Econometrica, 19 (3): 273-292.

Diewert, W. E. and T. J. Wales (1987): 'Flexible Functional Forms and Global Curvature Conditions', Econometrica, 55 (1): 43-68.

Farrel, M. J. (1957): 'The Measurement of Productive Efficiency', Journal of the Royal Statistical Society. Series A (General), 120 (3): 253-290.

Farsi, M., A. Fetz and M. Filippini (2008): 'Economies of scale and scope in multiutilities', Energy Journal, forthcoming.

Farsi, M., A. Fetz and M. Filippini (2007a): 'Benchmarking and Regulation in the Electricity Distribution Sector', In Servizi Pubblici: Nuovo tendenze nella regolametazione nella produzione et nel finanziamento (M. Marrelli, F. Padovano and I. Rizzo, Eds), Franco Angeli, Milano, pp. 159-176.

Farsi, M., A. Fetz and M. Filippini (2007b). "Economies of scale and scope in local public transportation." Journal of Transport Economics and Policy, 41 (3): 345-361.

Farsi, M. and M. Filippini (2007). Cost Efficiency and Scope Economies in Multioutput Utilities in Switzerland, final report submitted to the State Secretariat for Economic Affairs (SECO), Bern, Switzerand.

Farsi, M., M. Filippini and W. H. Greene (2006), Application of Panel Data Models in Benchmarking Analysis of the Electricity Distribution Sector, Annals of Public and Cooperative Economics, 77 (3): 271-290.

Farsi, M., M. Filippini and W. Greene (2005). 'Efficiency Measurement in Network Industries: Application to the Swiss Railway Companies', Journal of Regulatory Economics, 28 (1): 65-86.

Farsi, M., M. Filippini and M. Kuenzle (2007). 'Cost Efficiency in the Swiss Gas Distribution Sector', Energy Economics, 29 (1): 64-78. 
Farsi, M., M. Filippini and M. Kuenzle (2006): 'Cost efficiency in regional bus companies: An application of new stochastic frontier models', Journal of Transport Economics and Policy, 40(1): 95-118.

Farsi, M., M. Filippini and M. Kuenzle (2005). "Unobserved Heterogeneity in Stochastic Cost Frontier Models: An Application to Swiss Nursing Homes”, Applied Economics, 37, 2127-2141.

Featherstone, A. M. and C. B. Moss (1994). "Measuring Economies of Scale and Scope in Agricultural Banking." American Journal of Agricultural Economics 76(3): 655-61.

Fraquelli, G., M. Piacenza and D. Vannoni (2004). "Scope and Scale Economies in Multi-Utilities: Evidence from Gas, Water and Electricity Combinations." Applied Economics 36(18): 2045-57.

Fried, H. O., C. A. Knox Lovell and S. S. Schmist (2008). 'Efficiency and Productivity', In The Measurement of Productive Efficiency and Productivity Growth, H. O. Fried, C. A. Knox Lovell and S. S. Schmidt (editors), Oxford University Press, Oxford, Chapter 1, 3-91.

Friedlaender, A. F. and W. Chiang (1983). "Productivity Growth in the Regulated Trucking Industry." Research in Transportation and Economics 1: 149-84.

Greene, William H. (2007): Econometric Analysis, 6th edition, Prentice Hall, Upper Saddle River, New Jersey.

Greene, William (2005a). "Reconsidering Heterogeneity in Panel Data Estimators of the Stochastic Frontier Model”, Journal of Econometrics, 126 (2): 269-303.

Greene, William (2005b). "Fixed and Random Effects in Stochastic Frontier Models”, Journal of Productivity Analysis, 23 (1): 7-32.

Greene, William (2004). "Distinguishing between heterogeneity and inefficiency: Stochastic frontier analysis of the World Health Organization's panel data on national health care systems”, Health Economics 13: 959-980.

Griffin, Ronald C., J. M. Montgomery and M. E. Rister (1987). "Selecting Functional Form in Production Function Analysis", Western Journal of Agricultural Economics, December 1987, pp. 216-227.

Heshmati, Almas (1998). "Efficiency measurement in rotating panel data”. Applied Economics, 30 (7): 919-930.

Jara-Diaz, S. R., E. Martinez-Budria and F. J. Ramos-Real (2003). "Adapting Productivity Theory to the Quadratic Cost Function: An Application to the Spanish Electric Sector." Journal of Productivity Analysis 20(2): 213-29.

Jondrow, J., I. Materov, K. Lovell, and P. Schmidt (1982): 'On the estimation of technical inefficiency in the stochastic frontier production function model' Journal of Econometrics, 19, 2/3 (August), 233-238.

Jorgenson, Dale W. (1963), "Capital Theory and Investment Behavior," American Economic Review, Vol. 53, No. 2, pp. 366-378.

Kopsakangas-Savolainen, M. and R. Svento (2008). 'Estimation of cost-effectiveness of the Finnish electricity distribution utilities', Energy Economics, 30 (2): 212229. 
Kumbhakar, S. C. and C. A. Knox Lovell (2000). Stochastic Frontier Analysis, Cambridge University Press, Cambridge.

Kumbhakar, S. C. (1991). "Estimation of technical inefficiency in panel data models with firm- and time-specific effects”. Economics Letters, 36 (1991): 43-48.

Kumbhakar, S. C. (1990). 'Production frontiers and panel data, and time varying technical inefficiency'. Journal of Econometrics, 46(1990): 201-211.

Meeusen, Wim, and Julien van den Broeck (1977). 'Efficiency Estimation From Cobb-Douglas Production Functions With Composed Error', International Economic Review, 18 (2), 435-444.

Murillo-Zamorano, Luis R. (2004), Economic Efficiency and Frontier Techniques, Journal of Economic Surveys, 18 (1): 33-77.

Pitt, M. and L. Lee (1981). "The measurement and sources of technical inefficiency in Indonesian weaving industry”, Journal of Development Economics, 9: 43-64.

Polachek, S. and B. Yoon (1996). "Panel estimates of a two-tiered earnings frontier" Journal of Applied Econometrics, 11, 169-178.

Saal, D. S., D. Parker and T. Weyman-Jones (2007). 'Determining the contribution of technical change, efficiency change and scale change to productivity growth in the privatized English and Welsh water and sewerage industry: 1985-2000', Journal of Productivity Analysis, 28:127-139.

Schmidt, P. and R. E. Sickles, (1984). Production Frontiers and Panel Data, Journal of Business and Economic Statistics, 2, 367-374.

Sickles, R. C. (2005). Panel estimators and the identification of firm-specific efficiency levels in parametric, semiparametric and nonparametric settings. Journal of Econometrics 126 (2): 305-334.

Simar, Leopold (1992). "Estimating Efficiencies from Frontier Models with Panel Data: A Comparison of Parametric, Non-parametric and Semi-parametric Methods with Bootstrapping”, The Journal of Productivity Analysis, 3, 171203.

Sing, M. (1987). "Are combination Gas and Electric Utilities multiproduct natural Monopolies?" Review of Economics and Statistics 69(3): 392-8.

Tsionas, E. G. (2002) 'Stochastic Frontier Models With Random Coefficients', Journal of Applied Econometrics, 17, 127-147.

Wang, H. and P. Schmidt (2002): “One-Step and Two-Step Estimation of the Effects of Exogenous Variables on Technical Efficiency Levels”. Journal of Productivity Analysis, 18, 129-144. 